\title{
Research on Higher Vocational Education Informatization and Teaching Practice
}

\author{
Kerong GAI, Haiming FENG \& Jinxiang ZENG \\ Mechanical and Electrical Engineering Department of Beijing Polytechnic College, No. 368, Shimen Road, \\ Shijingshan District, Beijing
}

\begin{abstract}
Education informatization has played an important role in improving the education management, teaching practice and service management and is inevitable in the education reform. However, the application of information technology in education and teaching is far to reach designated goals, especially on the integration of information technology and curriculum. This paper analyses the current situation of higher vocational education informatization, and offers proposals for the integration of information technology and curriculum and makes helpful exploration on IT application in the teaching practice. This paper is of practical significance and reference value to some extent on the widespread application of IT in education.
\end{abstract}

KEYWORDS: education informatization; curriculum integration; digitalized study environment; hydraulic and pneumatic-driven technologies

\section{INTRODUCTION}

IT application in the higher vocational education has become an important part of the higher vocational education reform. China has implemented a series of important projects, policies and measures in recent years. As a result, the information infrastructure for the higher vocational education has been put in place, and the online teaching platform, multimedia classroom, digital library and resource management platforms are prevailing in vocational colleges. However, due to the lack of effective guiding concept and implementation path for the application of information technology in practice, software applications and hardware facilities cannot properly match with each other during the informatization. And the information technology has not been effectively used in teaching practice and is far to reach the goal in its true sense in terms of the depth and the level of informatization. Therefore, to innovate effective modes for integrating information technology with curriculum and explore the proper implementation path are the critical issues in the higher education informatization.

\section{ANALYSIS ON THE CURRENT SITUATION OF HIGHER VOCATIONAL EDUCATION INFORMATIZATION}

\subsection{Education informatization is a necessary condition of education modernization}

Education informatization means the widespread application and promotion of the information technology in teaching and education field and departments. At present, IT-driven education modernization has become the common understanding and requirement of education reform and development. The National Outline for Medium and Long-term Education Reform and Development Plan (2010-2020) emphasizes that high attention should be attached to the revolutionary impact of information technology to education development. The 10-year Development Plan of Education Informatization (2011-2020) issued by the Ministry of Education especially puts forward to accelerating education informatization to meet the requirements on cultivation of high-quality technical talents: vocational education informatization, as an important pillar to support the cultivation of highquality laborers and skillful talents, should be particularly reinforced in the education informatization. 


\subsection{Strengthening application of information technology in teaching is a necessary means to improve the quality of higher vocational education in the new period}

At present China has more than 1,300 vocational colleges with the students admittance qualification, accounting for $61 \%$ of the total number of higher education institutes, which have topped universities with regard to the number of new student enrollment. In order to improve the quality of higher education, the first is to improve the teaching quality of higher vocational education. However, the vocational colleges have to face various problems, e.g. students have acted aimlessly in study, or shortsightedly in setting goals, or have poor basic knowledge, little interest in study, poor self-study or self-control ability of students.[1] They often sleep, or play mobile phone in class, or act absentmindedly or have little understanding to the teaching content. The students are in awe of study while teachers feel difficulty to teach. Consequently the designated teaching effect cannot be reached. Meanwhile students at vocational colleges show abilities in quickly accepting new things, or finding solutions to problems or making innovation. Therefore, the information technology can be used to stimulate students' initiative, enthusiasm and creativity, and interests in study, and encourage them to think independently, strengthen cooperation between colleges and enterprises in teaching while implementing in-process monitoring and quantified evaluation. Therefore it is more important to create an open, diversified, interactive, comprehensive digital learning environment with smart support for common experience of teachers and students at certain time, space and psychological environment.

\section{EXPLORATION AND ANALYSIS TO INFORMATIZATION OF HIGHER VOCATIONAL EDUCATION}

In recent years, the investment is heavy in software and hardware construction for education informatization at home and abroad, but has not produced notable contribution to improvement of teaching quality and comprehensive qualities of students. The main reasons behind the fact are the lack of the correct understanding to the effective integration of information technology with professional teaching practices and the absence of effective integration means and measures.

\subsection{Correct understanding of integration between information technology and curriculum is the premise of education informatization}

The relationship between information technology and curriculum experienced a process from the arguments on computer aiding teachers, computer acting as a tool, or information technology creating digital environment to the ideas of valuing integration of information technology and curriculum, including IT-based teaching design and development and application of relevant software and tools. In the 21st Century, Prof. Roblyer emphasized the significance and function of various teaching and learning theories in integrating educational technology in teaching for the first time.[2] The International Society for Technology in Education (ISTE) defines[3] the integration of information technology with curriculum in this way: "Curriculum integration with the use of technology involves the infusion of technology as a tool to enhance the learning in a content area or multidisciplinary setting." Prof. He Kekang of China defined the integration of information technology and curriculum[4] as "a teaching and learning pattern which effectively integrates the information technology in teaching of various disciplines to create an IT-based teaching environment and enable teachers to give play to their guiding role and reflect students' dominant position in study. It is characterized by "independence, exploration and cooperation changes the existing teaching structure into a new one combining the guiding role and dominant role."

Insufficient understanding to integration between information technology and curriculum will directly result in failure of integration and the designated goal cannot be reached.

\subsection{Structuring a digital learning environment is the foundation of education informatization}

Digitalization is a foundation of widespread IT application while a digitized learning environment is the foundation of education informatization. Prof. Li Kedong holds that digitized learning is to enable students to learn by use of digital resources in a digital environment[5][6]. The digital learning environment is characterized by online transmission, smart-processing and multimedia display of information and virtual teaching environment. The mainstream digital resources include video, audio, and online platforms, simulation system and hypertext co-sharing resources in multimedia form. The learning content is impact, standard, generated and smart. The data exchange and standard works between the learning resources and the learning system can effectively solve problems such as disorder of learning resources, lack of sharing and low-efficiency of search.

Moreover, with development of mobile Internet technology, mobile learning[7] is becoming increasingly popular. This learning style enables learners to learn in many locations at their time convenience as a supplement to the other learning 
styles. It needs to strengthen application and planning in teaching to improve the learning effect.

\subsection{Changing the teaching structure is critical to realize education informatization}

Outstanding teaching must rely on scientific teaching concepts and advanced educational technology. It starts from excellent teaching design. The teaching structure[8][9] will directly determine the relationship between teachers, students, teaching content and curriculum resources. How to integrate information technology with curriculum will have a significant impact to the choice of teaching content and teaching methods. Therefore, scientificity and feasibility of teaching should be given full attention. Relying on IT-based teaching design, various terminals and online learning platforms, the traditional classroom teaching can be effectively expanded to enable students to learn at many locations at their time convenience and systematically combining online and offline, curricular and extra-curricular learning. In class, teachers can change their role to an organizer and tutor of learning activities and after class, students can learn independently. Finally a teacher-led teaching structure will be formed with students as the main body of teaching. The information technology can be used for better tracking and support of question solving, data collection and analysis of the learning path so as to facilitate evaluation, feedback and improvement of teaching.

\section{RESEARCH ON HIGHER VOCATIONAL EDUCATION INFORMATIZATION'S PRACTICE}

This paper expounds on, with the IT-based education reform of hydraulic and pneumatic system design, installation and commissioning curriculum as example, how to integrate information technology and curriculum, and how to change the curriculum structure with information technology and how to improve the teaching effect.

The hydraulic and pneumatic system design, installation and commissioning curriculum is a basic course of the vocational education. The teaching content involves a wide range of knowledge, and the hydraulic and pneumatic components are large in quantity and complex in structure. The hydraulic circuit is sealed in the mechanical and electrical structures and can not be observed easily. And the working process of the hydraulic circuit is abstract, showing strong theoretic, systematic and logical features. The systematic learning resources are insufficient, especially the content on how to install components, experiences in circuit design, installation and commissioning, and field operation.
In the traditional teaching, students are in awe of learning this part of knowledge and teachers cannot find an effective way to teach such knowledge. Therefore, it is not easy to learn the courses of hydraulic and pneumatic systems for students of higher vocational education.

The IT-based curriculum reform is first implemented on the basis of analyzing students' cognition and learning needs, re-defines the teaching goals from the aspects of knowledge, skill and professional quality according to the competence analysis and talent fostering plan for the professional jobs, and emphasizes more on cultivation of independent learning capability and information literacy of students. Task-oriented, the curriculum reform requests students to complete the task of design, installation and commissioning of each unit. The task-driven mode enables students to master the basic principles of hydraulic and pneumatic transmission, working principles and features of the hydraulic and pneumatic systems, and complete cognition, selection and use of hydraulic and pneumatic components, and be able to complete design, installation and commissioning of typical hydraulic and pneumatic systems. This course will foster students' question analysis and trouble shooting capability and improve their professional quality.

According to the teaching goals and actual situation of students, the curriculum first develops the online learning platform and mobile Internet platform to effectively integrate the relevant teaching materials, reference books, industrial standards, typical cases, field criteria and other content, FluidSIM simulation software, animation, video and unit and micro class[10] of various components and circuits, passing-through-checkpoint games, micro learning center, quantified evaluation software and resources and tools of the lesson preparation center, create an excellent digital learning environment, reform the traditional classroom teaching structure by effectively expanding teaching process to beforeclass, in-class and after-school parts so as to optimize the teaching effect.

Before class, the teacher introduces the learning cell content and guide students to make self-study exploration, coordination and exchanges centering on the tasks set by the teacher. Students can check the learning schedule at WeChat, and choose the relevant units at the online learning platform. With the engineering scenario created with multimedia means, including video, Q\&A, micro class center, community forum, unit game, BBS, electronic note etc., teachers can guide students to learn the relevant basic knowledge independently, think over and complete the basic tasks before class. Teachers can learn about the self-study status of students from the data statistics of the Class Preparation Center, find out the key points of class teaching and carry out 
targeted classroom teaching according to the teaching focus and difficulties.

In class, teachers can make good use of the multimedia courseware, and teach with the use of animation, video and FluidSIM simulation software and other resources according to the teaching focus, difficulties and key points. With regard to the teaching organization form, students are the main body of teaching and teachers mainly coach and organize students to complete the learning tasks, and foster students' team learning capability. The traditional teaching mode will be reformed with the team cooperation and discussion, student-teacher interaction and other forms. The team selects components according to the task manual, and makes component layout, circuit connection and system commissioning. To address problems occurred in the process of installation and commissioning, students can learn at the "Installation and Commissioning Resource Center" and from the teachers' instruction and demonstration. This process not only sharpens students' independent analysis and problem-solving capability, but also strengthens their communication, exchange and coordination capability. By continuously experiencing bitterness of failure and joy of success in the process of learning, students can consolidate their confidence.

After class, students can make extensive study at the after-school expansion module. The learning platform will push personalized knowledge points according to students' electronic note and knowledge label so that they can consolidate and expand their learning purposely. Students can go over the difficulties and key points by watching the video teaching materials. After school, students can $\log$ on the micro leaning platform of hydraulic and pneumatic technology and study the relevant knowledge and experiences according to their own plan, and make personalized reading and interactive exchanges and communicate with experts of partnering enterprises on issues of interests to deepen cooperation between the schools and enterprises in teaching.

The evaluation to students is conducted by the multifaceted comprehensive evaluation center. In addition to task reporting and oral examination, professional quality evaluation, the other evaluation is supported and structured with the use of information technology, including the team online testing, personal online testing, electronic task report evaluation, and learning path evaluation. With the complicated calculation of the system, students will be scored on six aspects, "knowledge", "skill", "method", "coordination", "self-study" and "other qualities". The radar chart is used to show the evaluation of students' learning effect, and point out the next-step direction. This result will be included in the personal curriculum growth archive of the students for the exploration of new type evaluation methods to drive students' study capability with evaluation.

\section{CONCLUSIONS}

Relying on the online learning platform and mobile Internet platform, the hydraulic and pneumatic technology course has effectively integrated the teaching resources, reformed the teaching structure, optimized the teaching process in an attempt to create a digital learning environment that combines the guiding role of teachers, personalized exploration, smart tutorship and learning, independent cooperation and evaluation-driven learning and other elements. The effective integration of information technology with curriculums makes the static knowledge dynamic, abstract knowledge visual and learning content in recreational and fragment forms. In this way, the teaching process meets the cognition law of students of higher vocational education and enables students to fully absorb the knowledge. The evaluation center reforms the evaluation methods, monitors the learning process, and changes the learning effect reflection form and realizes diversified, scientific, convenient and multifaceted comprehensive evaluation to the learning process and learning result.

After several years of continuous reform and practice, the application of information technology in education has diversified the teaching means, offered opportunities for engineers of enterprises to effectively participate in teaching, and improved students' interests in study. Consequently, students have a stronger foundation of professional knowledge, outstanding technological capability and significantly improved professional quality. A good teaching effect has been achieved, showing a promotion value to some extent.

However, the classroom teaching is a dynamic, interactive and changing process. And the complexity of teaching subject leads to various uncertainties and possibilities in answering and solving the questions in teaching. This requires teachers to continuously update their informatization quality, enhance the teaching design applicability and teaching scenario pre-plan capability, and regularly evaluate and improve teaching effect. Thus, the teaching practice can better stimulate students' thinking, create learning opportunities, exceed and sublime the previous teaching experiences. 


\section{REFERENCES}

[1] Kerong Gai, 2013.Research on Basic Quality Education of Higher Vocational Education. Education and Career. (10), 101-103.

[2] M.D Roblyer. Integrating Educational Technology into Teaching. http://wps.prenhll.com/chet_roblyer_integration_3.

[3] National Educational Technology Standards for Teachers. http://www.cnets.org.

[4] Ke Kekang. 2008. Theory on In-depth Integration betweenInformation Technology and Curriculum, Beijing, Beijing Normal University Publishing Group.

[5] Li Kedong. 2001. Digital Learning - Core of Integration between Information Technology and Curriculum (I), EEducation Research. (8): 39-54.
[6] Li Kedong.2001.Digital Learning - Core of Integration between Information Technology and Curriculum (II), EEducation Research (9): 18-22.

[7] Huang Huairong, Wang Xiaochen, Li Yushun, 2009. Learning Activity Design Framework towards Mobile Learning, Remote Education Magazine. (1): 3-7.

[8] He Kekang. 2007. Teaching Structure Theory and Deepening Education Reform (I), E-Education Research. (7): 5-10.

[9] He Kekang. 2007. Teaching Structure Theory and Deepening Education Reform (II), E-Education Research. (8): 22-27.

[10] Yang Liming. 2013. On Intensive Integration of Information Technology and Education and Teaching Reform, Vocational and Technical Education Forum. (36). 